\title{
Commentary: Concurrent Imitative Movement During Action Observation Facilitates Accuracy of Outcome Prediction in Less-Skilled Performers
}

\author{
Wacław Petryński* \\ Katowice School of Economics, Katowice, Poland
}

Keywords: Bernstein's theory, modalities' ladder, motor scenario, motor habit, tactics

\section{A Commentary on}

Concurrent Imitative Movement During Action Observation Facilitates Accuracy of Outcome Prediction in Less-Skilled Performers

by Unenaka, S., Ikudome, S., Mori, S., Nakamoto, H. (2018). Front. Psychol. 9:1262. doi: 10.3389/fpsyg.2018.01262

OPEN ACCESS

Edited by:

Pietro Avanzini,

Università degli Studi di Parma, Italy

Reviewed by:

Francesca Federico,

Sapienza Università di Roma, Italy

*Correspondence:

Wacław Petryńsk

waclaw.petrynski@interia.pl

Specialty section:

This article was submitted to

Movement Science and Sport

Psychology,

a section of the journal

Frontiers in Psychology

Received: 01 September 2018 Accepted: 29 November 2018

Published: 18 December 2018

Citation:

Petryński W (2018) Commentary:

Concurrent Imitative Movement

During Action Observation Facilitates

Accuracy of Outcome Prediction in Less-Skilled Performers.

Front. Psychol. 9:2561.

doi: 10.3389/fpsyg.2018.02561
In the paper "Concurrent Imitative Movement during Action Observation Facilitates Accuracy of Outcome Prediction in Less-Skilled Performers" Unenaka et al. (2018) have presented the comparison of experimental results obtained in groups of skilled and less skilled basketball players.

Their results remain in good compatibility with the conceptual models of modalities' ladder (Petrynski, 2014, 2016, p. 60; Petrynski, 2018) and movements' management matrix (Petrynski, 2016, p. 133). Both they are based on the theory of Bernstein $(1947,1996)$.

Let us term the "motor operation" an intentionally organized set of movements, aimed at solving of a specific task in environment (Petrynski, 2016, p. 14). While taking as a base the Bernstein's theory, it is possible to invent the modalities' ladder, i.e., a hierarchical system of information processing modalities, internal motor operation patterns, particular classes of motor operations, and movements' control modes as presented in Table 1.

Politics means adjusting the external conditions to the planned (usually not realizable here and now) performance rather, and not embedding any realizable performance in physically existing environment.

The researches presented by Unenaka et al. concern the C-level (Petrynski, 2016, p. 26; Petrynski, 2018). At that level, the mechanism of imitation is supported by activity of mirror neurons Rizzolatti, 2005. They make an innate system (i.e., being a part of a biological "hardware" rather, and not "software"), supporting the process of imitation, being an important learning mechanism in animals and humans.

Creation of the internal motor operation patterns is aimed at reducing the "intellectual costs" and thus enhancing the efficiency of a motor operation. While not yet fully shaped, such a pattern needs feedback control mode, typical for learning process. It is time-consuming and "expensive" in terms of mental effort, because it needs identification of physical stimuli in environment, associating them with the just being performed operation and creation of possible corrections. In short, it needs engagement of precious attention. Such a mechanism is typical for less-skilled performers, e.g., basketball players. 
TABLE 1 | The modalities' ladder.

\begin{tabular}{lllll}
\hline $\begin{array}{l}\text { Bernstein's } \\
\text { level }\end{array}$ & Information processing modality & Internal motor operation pattern & Class of a motor operation & Movements' control mode \\
\hline E & Symbolic & No real motor operation pattern & No real motor operation & Politics \\
D & Verbal & Program & Performance & Strategy \\
C & Teleceptive, mainly visual & Scenario & Habit & Tactics, "measure-in-eye" \\
B & Contactceptive, mainly haptic & Template & Automatism & Technique, movements' harmony \\
A & Proprioceptive & Coupling & Reflex & Strength control, \\
& & & & "feeling-in-hand" \\
\hline
\end{tabular}

When a specific motor operation pattern (at C-levelscenario; Petrynski, 2016, p. 52; Petrynski, 2018) is already fully shaped, the intellectual cost decreases, and efficiency increases. A skilled basketball player disposes of reliable scenarios, ready to immediate use, hence s/he does not need any more to detect and identify the extrinsic stimuli (i.e., to engage attention), like in the process of learning. S/he switches to swift feedforward control mode and does not need any more a current (or concurrent) extrinsic informational support.

In the movements' management matrix model there is no dichotomous division: feedback (attention on)-feedforward (attention off). Somewhere in the midway there is a "stand by" state of attention-less "expensive" than "full feedback," but not as "cheap" (in terms of attention engagement) as "full feedforward." Hence, in the movements' management matrix the feedback and feedforward control modes make a continuous space, with attention fully active, more or less "sleeping," and completely inactive.

If the feedforward (intrinsic control) becomes stronger than the influence of feedback (extrinsic stimuli), then the mental selfconfidence may not overlap with a genuine reliability. Intentional provoking of such a false self-confidence makes an essence of, e.g., faking in sport.

\section{REFERENCES}

Bernstein, N. A. (1947). O Postroyenii Dvizheniy (On Construction of Movements). Moscow: Medgiz.

Bernstein, N. A. (1996). "On dexterity and its development," in Dexterity and Its Development, eds M. L. Latash and M. T. Turvey (Mahwah, NJ: Lawrence Erlbaum Associates), 1-244.

Clark, A. (1993). Microcognition: Philosophy, Cognitive Science and Parallel Distributed Processing. Cambridge, MA: MIT Press.

Gerrig, R. J. (2013). Psychology and Life. 20th edn. Upper Saddle River, NJ: Pearson Education.

Gibbon, E. (1995). The Decline and Fall of the Roman Empire. Harmondsworth, Middlesex: Penguin Books.

Petrynski, W. (2014). Consciousness - a system-theoretical approach. Front. Psychol. 5:115. doi: 10.3389/fpsyg.2014.00115

Petrynski, W. (2016). Motor Control in Humans. A System-Theoretical Approach. Hauppauge, NY: Nova Science Publishers.

Petrynski, W. (2018). Formation of the sensorimotor operation pattern from a system-theoretical perspective. Int. J. Phys. Educ. Fitness Sports 7, 30-42. doi: 10.26524 /ijpefs 1825
Both the control modes-feedback, typical for less-skilled performers, and feedforward, used by skilled ones-may be also joined with the crystallized and fluid intelligence, respectively, as by R. Cattell (Gerrig, 2013, p. 248).

It seems instructive to conclude this comment with the remark of eighteenth century historian E. Gibbon, who stated, "the power of instruction is seldom of much efficacy, except in those happy dispositions where it is almost superfluous" (Gibbon, 1995, p. 79). Such an "informational frugality" makes also the essence of Bernstein's degrees of freedom reduction rule (Bernstein, 1947, p. 20), which enables transformation of non-controllable movements' creation systems into controllable ones. While perceived dynamically, it may be associated with the most advanced quality of attention, i.e., its switchability. It is also congruent with the "007 Principle" by A. Clark: "... to know only as much as you need to know to get the job done." (Clark, 1993, p. 64).

\section{AUTHOR CONTRIBUTIONS}

The author confirms being the sole contributor of this work and has approved it for publication.

Rizzolatti, G. (2005). “The mirror neuron system and imitation,” in Perspectives on Imitation: From Neuroscience to Social Science. Volume 1. Mechanisms of Imitation and Imitation in Animals, eds S. Hurley and N. Chater (Cambridge, MA: MIT Press), 55-76.

Unenaka, S., Ikudome, S., Mori, S., and Nakamoto, H. (2018). Concurrent imitative movement during action observation facilitates accuracy of outcome prediction in less-skilled performers. Front. Psychol. 9:1262. doi: 10.3389/fpsyg.2018. 01262

Conflict of Interest Statement: The author declares that the research was conducted in the absence of any commercial or financial relationships that could be construed as a potential conflict of interest.

Copyright (C) 2018 Petrynski. This is an open-access article distributed under the terms of the Creative Commons Attribution License (CC BY). The use, distribution or reproduction in other forums is permitted, provided the original author(s) and the copyright owner(s) are credited and that the original publication in this journal is cited, in accordance with accepted academic practice. No use, distribution or reproduction is permitted which does not comply with these terms. 